\title{
Universal antenatal screening for group B streptococcus may cause more harm than good
}

Based on current evidence, routine screening for group B streptococcus colonisation in late pregnancy should not be introduced in the UK, as the potential harms of unnecessary treatment with antibiotics may outweigh the benefits, argue Farah Seedat and colleagues

Farah Seedat doctoral candidate ${ }^{1}$, Julia Geppert research fellow ${ }^{1}$, Chris Stinton senior research fellow ${ }^{1}$, Jacoby Patterson clinical effectiveness reviewer ${ }^{1}$, Karoline Freeman research fellow ${ }^{1}$, Samantha Ann Johnson academic support librarian ${ }^{1}$, Hannah Fraser research associate ${ }^{1}$, Colin Stewart Brown consultant microbiologist ${ }^{2}$, Olalekan A Uthman associate professor ${ }^{1}$, Bee Tan professor $^{4}$, Esther R Robinson lead public health microbiologist ${ }^{3}$, Noel Denis McCarthy professor ${ }^{1}$, Aileen Clarke professor ${ }^{1}$, John Marshall evidence lead ${ }^{5}$, Cristina Visintin senior evidence review manager $^{5}$, Anne Mackie professor ${ }^{5}$, Sian Taylor-Phillips associate professor ${ }^{1}$

'Division of Health Sciences, University of Warwick Medical School, Gibbet Hill Campus, Coventry CV4 7AL, UK; ${ }^{2}$ Bacteria Reference Department, National Infection Service, Public Health England, London, UK; ${ }^{3}$ Field Service, National Infection Service, Public Health England, Nottingham, UK; ${ }^{4}$ Department of Cardiovascular Sciences, Robert Kilpatrick Clinical Sciences Building, University of Leicester, LE2 7LX, UK; ${ }^{5}$ UK National Screening Committee, London, UK

\section{Key messages}

Early onset group B streptococcus (GBS) disease is an important health problem and efforts should continue to better understand and prevent it

Selective maternal culture is not an accurate test to predict early onset GBS disease in neonates, and we don't know why some colonised mothers have a neonate with early onset GBS and others don't

The current approach to screening would lead to $99.8 \%$ of screen positive women and their babies receiving unnecessary intrapartum antibiotic prophylaxis

Lack of high quality evidence on clinical outcomes makes it impossible to quantify whether universal GBS screening would have any benefit and assess whether large scale intrapartum antibiotic prophylaxis is safe A universal antenatal culture screening programme cannot currently be recommended

Group B streptococcus (Streptococcus agalactiae, GBS) is the most common cause of neonatal sepsis and meningitis in many developed countries. ${ }^{1}$ In the UK, GBS causes invasive disease in the first six days of life (early onset GBS infection) in around one of every 2000 live births. ${ }^{2}$ To prevent early onset disease, intrapartum antibiotic prophylaxis, usually intravenous penicillin, is the recommended treatment internationally. The UK recommends a risk based strategy, whereby pregnant women presenting with risk factors for early onset GBS infection are offered antibiotic prophylaxis in labour. ${ }^{3-6}$
The media and politicians regularly call for universal antenatal screening for GBS as an alternative means of selecting women for prophylaxis. Advocates point to countries across Europe and North America where screening is recommended ${ }^{7-19}$ and where reductions in early onset GBS infection have been observed. ${ }^{20-22}$ But the evidence shows that the effectiveness of screening, using established screening criteria, ${ }^{23}$ is uncertain and that screening has potential harms. Here, we explain why the UK National Screening Committee decided not to introduce routine screening in the $\mathrm{UK}^{24} 25$-namely, high levels of overtreatment, unknown potential hazards from screening and intrapartum antibiotic prophylaxis treatment, and uncertain benefit.

\section{Impact of GBS}

GBS is a Gram positive bacterium that colonises the gastrointestinal and genitourinary tracts in approximately $20 \%$ of pregnant women. ${ }^{2627}$ It usually causes no harm, ${ }^{8}$ but if a woman is colonised at the time of labour, around $36 \%$ will transmit the bacteria to their newborn child. ${ }^{28}$ Crucially, the majority of neonates colonised with GBS remain asymptomatic, but about 3\% develop early onset infection. ${ }^{28}$ In the UK and Republic of Ireland the incidence is estimated at 0.57 per 1000 live births $(\mathrm{n}=517) .^{2}$ Affected neonates present with sepsis in $63 \%$ of cases, pneumonia in $24 \%$, meningitis in $13 \%,{ }^{29}$ and around $5-10 \%(\mathrm{n}=27-38)$ die as a result..$^{302}$ Neurological 
impairment is reported in up to $16 \%$ of cases who survive infection, ${ }^{31-33}$ though long term outcomes are not well researched. The true burden of early onset GBS infection is likely to be higher, as most of the research only describes cases confirmed by culture, and the infecting organism cannot be isolated in approximately half of neonatal sepsis cases. ${ }^{34}$ It causes considerable morbidity and mortality.

A risk based strategy to prevent early onset GBS infection has been recommended in the UK since 2003..$^{3-6}$ Pregnant women presenting with preterm labour, GBS colonisation, a previous infant with GBS disease, GBS bacteriuria, intrapartum fever, or chorioamnionitis are offered intrapartum antibiotic prophylaxis. ${ }^{3-6}$ But $65 \%$ of neonates with early onset GBS infection are born to mothers who have no risk factors and are therefore not eligible. ${ }^{2}$

\section{Universal GBS screening}

Screening comprises the collection of specimens from rectovaginal swabs at 35 to 37 weeks' gestation, which are processed using selective culture media to identify women colonised with GBS. ${ }^{35}$ Screening would be offered to all pregnant women at term and could detect some of the $65 \%$ of neonates with early onset GBS infection born to mothers without risk factors.

Screening was first introduced in the US in 1996, where the incidence of culture confirmed early onset GBS infection was around 1.7 per 1000 live births. ${ }^{21}$ After the 1996 recommendation that either risk based or screening strategies could be implemented, the incidence fell to 0.4 per 1000 in 2001 . After the recommendation that screening should be implemented in 2002 , the incidence fell further, to 0.3 per 1000 in 2004. ${ }^{22}$ Screening has continued since and the incidence was estimated at 0.22 per 1000 live births in $2016 .{ }^{36}$ Most countries that recommend screening have seen a similar reduction or stabilisation in the incidence of early onset disease, ${ }^{20}{ }^{37}$ though some have not. ${ }^{38}$

In the UK and Republic of Ireland, which have risk based prevention rather than screening, the incidence is much lower than in the US before screening, at 0.57 per 1000 live births in 2014-15. ${ }^{2}$ But it has risen significantly from 0.48 per 1000 in 2000-01, before national guidelines were published. ${ }^{392}$ [6] The reasons for this are unclear.

\section{Overdiagnosis and potential harm}

Given that only a small percentage of neonates born to women colonised with GBS get infected, the proposed screening programme would make many women eligible for prophylaxis whose babies would not have developed early onset infection if left untreated. Based on UK data, antenatal culture would correctly predict early onset infection in around two of every 1000 pregnant women $(0.2 \%)$ with a positive result (fig 1$)$. In 2000-01, under no national prevention guideline, 126159 term pregnant women were colonised with GBS, but only 205 term neonates developed early onset infection, meaning screening would have led to overtreatment of 125954 (99.8\%) women in labour. Similarly, in 2014-15, under risk based prevention, 138 933 term pregnant women were colonised with GBS, but only 350 term neonates developed early onset infection, meaning screening would have led to overtreatment of $138583(99.75 \%)$ women in labour.

This positive predictive value of $0.2 \%$ would deliver an extremely high rate of false positive results, all of whom would be overtreated with intrapartum antibiotics. A cost effectiveness model published in 2007 also estimated that adding screening to risk based prevention would result in around $99.8 \%$ overtreatment and would increase antibiotic use in pregnancy from $11 \%$ to $27 \% .{ }^{44}$ Recently, an expert group convened by the UK National Screening Committee published a modelling exercise concluding that adding screening to a risk based strategy in the UK would result in an additional 1675-1854 women receiving intrapartum antibiotic prophylaxis to prevent one case of early onset GBS infection, and 24 065-32 087 to prevent one death due to early onset GBS infection. ${ }^{43}$ Similarly, an Australian centre reported that 1191 women would need to be treated with intrapartum antibiotic prophylaxis to prevent one case of early onset GBS infection. ${ }^{45}$ Although the models have some limitations because of evidence gaps, the estimates support the high levels of overtreatment that would occur.

Thus, examining the potential harms of GBS screening is important. A systematic review of 30 studies of intrapartum antibiotic prophylaxis found little evidence to quantify the potential harms to mothers and babies. ${ }^{46}$ Although a range of adverse effects was investigated, the 11 studies in which the authors explicitly stated that they examined prophylaxis for GBS were observational and at risk of bias. The 13 randomised controlled trials at lower risk of bias investigated antibiotics and regimens different from GBS prophylaxis. Key findings were around changes in gut microbiota, ${ }^{47-54}$ long term functional impairment, ${ }^{55}$ and antibiotic resistance. ${ }^{526-60}$

There was consistent observational evidence that intrapartum antibiotic prophylaxis for GBS alters neonatal gut microbiota. ${ }^{47-54}$ Changes to gut microbiota have been associated with metabolic problems (such as obesity and diabetes), atopic, inflammatory, and autoimmune problems (such as asthma and necrotising enterocolitis), and autism. ${ }^{61-63}$ Early antibiotic exposure has also been associated with these long term clinical outcomes. ${ }^{61-64}$ Causal links, however, have not been established, and we don't know whether microbiota alterations specifically from GBS prophylaxis are associated with any long term clinical outcomes.

The review found inconsistent results for the effect of prophylaxis on antibiotic resistance, with evidence of increased resistance for some antibiotics and pathogens and no increase for others. ${ }^{5256-60}$ Globally, the overwhelming majority of GBS isolates are susceptible to penicillin, ${ }^{65}$ but in the US in 2005, $0.2 \%$ of GBS isolates were reaching the upper level of susceptibility for one or more $\beta$ lactams. ${ }^{66}$ Widespread prophylaxis may go against the Department of Health and Social Care for England's antimicrobial resistance strategy to reduce unnecessary use of antibiotics. ${ }^{67}$ Finally, the review reported a lack of information on the long term outcomes of intrapartum antibiotic prophylaxis. Evidence from only one randomised controlled trial using antibiotics for spontaneous preterm labour showed that antibiotic use was moderately associated with serious consequences of functional impairment at 7 years of age. ${ }^{55}$ This study has applicability concerns, however, as the antibiotics differed from those given for GBS and were given for a longer duration.

Maternal anaphylaxis is another important harm to consider, as it has potentially fatal consequences. But its rarity makes it difficult to explore in well designed studies other than very large randomised controlled trials. In the US, four cases of anaphylaxis associated with GBS prophylaxis were reported after the introduction of guidelines in 1996 up to $2010 .^{68}$ The rate of all cause maternal anaphylaxis in the UK has been reported at 1.6 per 100000 maternities - 37 cases in three years, 11 due to penicillin and one the result of GBS prophylaxis. Two mothers (5\%) died; 14 (38\%) mothers and seven $(41 \%)$ neonates required intensive care admission. ${ }^{6970}$ 
Other reported harms include neonatal respiratory distress, ${ }^{71}$ maternal thrush, ${ }^{72}$ and childhood atopic dermatitis. ${ }^{73}$ Antibiotic prophylaxis in labour may also limit birth choices for women and contribute to the medicalisation of labour. ${ }^{4}$ Drawing conclusions on the harms of screening is difficult, however, as the evidence is based mainly on small observational studies, subject to bias, or has applicability concerns.

\section{Uncertain evidence on screening effectiveness}

The evidence on clinical effectiveness of GBS screening is observational and focuses on incidence rather than clinical outcomes. No randomised controlled trials have assessed the effects of screening on the incidence of early onset GBS infection, clinical outcomes, or mortality. In the absence of randomised controlled trial data, quantifying the potential impact of adding screening to risk based practice is difficult. Most observational evidence shows no difference in mortality due to early onset GBS infection between risk based and screening prevention, ${ }^{746}$ and we do not know the difference in the long term clinical outcomes of early onset GBS infection between the two strategies. These studies, however, may be underpowered to detect differences in these rare outcomes. Studies examining all cause early onset sepsis have been contradictory. ${ }^{77-79}$

A systematic review of nine observational studies from Turkey, Australia, and the US found that the odds of early onset GBS infection under universal screening were $55 \%$ lower than under risk based prevention for all neonates and for term neonates (three studies). ${ }^{80}$ A 2017 study in a UK maternity unit found that the rate of early onset GBS infection fell from 0.99 per 1000 live births in the risk based period to 0.33 per 1000 in the screening period, although this was not statistically significant, and screening was instigated based on high incidence so there may have been regression to the mean.$^{81}$ In a follow-on study, the authors found that incidence of early onset GBS infection had risen to 1.79 per 1000 live births after screening was stopped, which was statistically significant when adjusting for ethnicity. ${ }^{82}$

The well documented risk of bias in observational study designs is due to confounding and the inability to determine cause and effect. ${ }^{838}$ The majority of studies on GBS screening compare the incidence of early onset infection in a period of screening against a historical control period (that is, risk based prevention). ${ }^{74-7685-88}$ Risk of bias is higher in these studies because participants in the two arms are not contemporaneous, so other differences between these periods may contribute. The few observational studies that compare screening with concurrent controls often retrospectively compare women who have a culture result to all other women ${ }^{89}$; ; this may be biased due to the risk of misclassification and because people who accept screening are systematically different from those who do not. ${ }^{8091}$ Finally, as most studies only assess early onset GBS infection confirmed on culture, changes in disease incidence may actually reflect a decreased likelihood of culturing GBS in the laboratory, owing to the presence of antibiotics in neonates' blood..$^{92}$ This could distort the effect of screening and may explain why studies examining early onset GBS infection confirmed on culture find a reduction in incidence between screening and risk based prevention, when studies assessing mortality or all cause neonatal sepsis find no difference. Because of these limitations, the effectiveness of universal GBS screening is uncertain.

\section{Conclusions}

GBS infection is an important health problem, and we need more work to understand and prevent neonatal disease. Universal GBS screening is a complex area, and the current uncertain evidence about whether screening would do more good than harm emphasises the problem of introducing a new screening programme. Selective maternal culture is not an accurate predictor of early onset GBS disease in neonates. If a GBS screening programme was implemented, it would offer all term pregnant women the culture test, but around $99.8 \%$ of mothers who screen positive (and their babies) would experience overdiagnosis and would be offered intrapartum antibiotic prophylaxis unnecessarily. The harm from widespread prophylaxis to thousands of pregnant women and their babies is unknown, and the evidence for benefit from screening is uncertain owing to lower quality studies with serious limitations.

The Health Technology Assessment programme recently launched a call for a randomised controlled trial assessing the effectiveness of GBS screening, which may tackle this uncertainty. But we also need research assessing the potential harms before we can be confident that screening is safe. Being able to more accurately identify the women at most risk of having a neonate with early onset GBS infection could reduce the amount of overtreatment. Alternatively, advances are under way in the development of a GBS vaccine, which would affect all antibiotic based preventive strategies and have the potential to prevent early and late onset GBS infection. ${ }^{93}$

We thank Michael Millar, Arlene Reynolds, and Magdalena Skrybant for providing advice and input, and Nick Johnstone-Waddell for providing graphical input.

Competing interests: The research underpinning this analysis article was commissioned by the UK National Screening Committee (NSC). ST-P, CS, HF, JG, and AC are supported by the National Institute for Health Research CLAHRC West Midlands initiative. ST-P is supported by an NIHR Career Development Fellowship. AM is the director of the UK NSC, JM is the evidence lead and CV is an evidence review manager for the UK NSC. The views expressed in this paper are those of the authors and not necessarily those of the NHS, the National Institute for Health Research, Public Health England, or the Department of Health. Any errors are the responsibility of the authors.

Data sources and contributors: The sources of information used to prepare this manuscript are from the UK NSC policy reviews of 2012 and 2016, in addition to the GBS model that was developed by the UK NSC, and studies on GBS epidemiology and screening published after the 2016 NSC review. This piece of research and the completion of this manuscript involved a multidisciplinary team of information specialists, epidemiologists, infectious disease, microbiology, and obstetrics and gynaecology consultants, screening and public health specialists, statisticians, and reviewers. AM, JM, and CV contributed to the writing of this manuscript but did not conduct any of the review processes or the synthesis and interpretation of the original reviews. The research team below conducted the 2016 NSC review for GBS. FS has completed a PhD specialising in GBS screening and has previously conducted systematic reviews, including NSC reviews; FS secured funding, coordinated the review process, developed the protocol, created and applied the search strategy to collect the data, sifted, extracted, and quality assessed $20 \%$ of the articles, and synthesised the data for the 2016 review. FS also combined the evidence from the 2012 and 2016 NSC evidence reviews selecting the best available evidence for this article and led the writing of this manuscript. JG is an expert systematic reviewer specialising in screening and test accuracy and has previously conducted NSC reviews; JG carried out data sifting, extraction, quality assessment, and synthesis for all the data for the 2016 review, reviewed the merging of data between the 2012 and 2016 evidence reviews, and reviewed the manuscript for redrafting. OU, CS, and KF are also expert systematic reviewers who have conducted previous reviews for the NSC and health technology assessments for NICE; they contributed to protocol development for the 2016 review and reviewed this manuscript for redrafting. JP is a medical doctor with 
expertise in evidence based medicine and systematic reviews who has conducted NSC reviews; JP reviewed this manuscript for redrafting. NM is an academic public health physician and epidemiologist with expertise in infectious disease control, ER is the lead public health microbiologist for East Midlands Public Health England, and $\mathrm{CB}$ is a consultant in infectious diseases and medical microbiology at Public Health England; they contributed to protocol development for the 2016 review and reviewed this manuscript for redrafting, providing expertise on infection and microbiology. BT is a clinician scientist, consultant obstetrician and gynaecologist, and RCOG accredited subspecialist in reproductive medicine who has managed numerous patients with GBS in pregnancy; BT contributed to protocol development for the 2016 review and reviewed this manuscript for redrafting, providing obstetrics and gynaecology expertise. $\mathrm{S} J$ is an academic support librarian and $\mathrm{HF}$ has studied the masters in screening course; they contributed to protocol development, search strategy development, and data collection of the 2016 review, and reviewed this manuscript for redrafting. AC is a clinical public health academic who heads the Division of Health Sciences at the Warwick Medical School and leads one of nine technology assessment review teams providing systematic reviews to NICE; AC contributed to protocol development for the 2016 review and reviewed this manuscript for redrafting. ST-P is an associate professor of screening and test evaluation with wide experience in systematic reviews specialising in screening, including NSC reviews; ST-P secured the funding, coordinated the review process, developed the protocol for the 2016 review, and reviewed this manuscript for redrafting. ST-P is the guarantor.

Provenance and peer review: Not commissioned; externally peer reviewed

1 Le Doare K, Heath PT. An overview of global GBS epidemiology[published Online First: 2013/08/30]. Vaccine 2013;31(Suppl 4):D7-12. 10.1016/j.vaccine.2013.01.009 23973349 2 O'Sullivan CP, Lamagni T, Patel D, etal . Group B streptococcal disease in UK and Irish infants younger than 90 days, 2014-15: a prospective surveillance study. Lancet Infect Dis 2019;19:83-90.30497953

3 National Institute for Health and Clinical Excellence. Antibiotics for early-onset neonatal infection: antibiotics for the prevention and treatment of early-onset neonatal infection. National Institute for Health and Clinical Excellence, 2012.

4 Royal College of Obstetricians and Gynaecologists. Prevention of early onset neonatal group B streptococcal disease. Guideline no 36. 1st ed. Royal College of Obstetricians and Gynaecologists, 2003.

5 Royal College of Obstetricians and Gynaecologists. Prevention of early onset neonatal group B streptococcal disease. Guideline no 36. 2nd ed. Royal College of Obstetricians and Gynaecologists, 2012.

6 Royal College of Obstetricians and Gynaecologists. Prevention of early onset neonatal group B streptococcal disease. Guideline no 36 . 3rd ed. Royal College of Obstetricians and Gynaecologists, 2017. https://www.rcog.org.uk/en/guidelines-research-services/ guidelines/gtg36/

7 Homer CS, Scarf V, Catling C, Davis D. Culture-based versus risk-based screening for the prevention of group $B$ streptococcal disease in newborns: a review of national guidelines. Women Birth 2014;27:46-51. 10.1016/j.wombi.2013.09.006 24239269

8 Rodriguez-Granger J, Alvargonzalez JC, Berardi A, etal . Prevention of group B streptococcal neonatal disease revisited. The DEVANI European project. Eur J Clin Microbiol Infect Dis 2012:31:2097-104. 10.1007/s10096-012-1559-0 22314410

9 Royal Australian and New Zealand College of Obstetricians and Gynaecologists. Maternal Group B Streptococcus in pregnancy: screening and management, C-Obs 19. RANZCOG, 2016.

10 Money D, Allen VMInfectious Diseases Committee. The prevention of early-onset neonatal group B streptococcal disease. J Obstet Gynaecol Can 2013;35:939-48. 10.1016/S1701-2163(15)30818-5 24165063

11 Money DM, Dobson SCanadian Paediatric Society, Infectious Diseases Commitee. The prevention of early-onset neonatal group B streptococcal disease. J Obstet Gynaecol Can 2004;26:826-40. 10.1016/S1701-2163(16)30157-8 15361281

12 Canadian Task Force on Preventive Health Care. Prevention of group B streptococcal infection in newborns: recommendation statement from the Canadian Task Force on Preventive Health Care. CMAJ 2002;166:928-30.11949992

13 Melin P. Prevention of perinatal group B streptococcal diseases: Belgian guidelines. Round Table Series - Royal. Soc Med (Soc Med Publ Group) 2007;85:29-41.

14 Melin P, Verschraegen G, Mahieu L, Claeys G, Mol PD. Towards a Belgian consensus for prevention of perinatal group B streptococcal disease. Indian J Med Res 2004;119(Suppl):197-200.15232194

15 Agence Nationale d'Accreditation et d'Evaluation en Sante. Antenatal prevention of early neonatal bacterial infection-Clinical practice guidelines. ANAES, 2001. https://webzine. has-sante.fr/portail/upload/docs/application/pdf/Antenatal prevention.pdf

16 Berufsverband der Frauenärzte e.V. (BVF) BDfKeVB, Deutsche Gesellschaft für Gynäkologie und Geburtshilfe (DGGG), Deutsche Gesellschaft für Hygiene und Mikrobiologie (DGHM) DGfPID, et al. Prophylaxe der Neugeborenensepsis - frühe Form - durch Streptokokken der Gruppe B: AWMF, 2016. https://www.awmf.org/uploads/tx szleitlinien/024-020I_S2k_Prophylaxe_Neugeborenensepsis_Streptokokken_2016-04. pdf

17 Società Italiana di Medicina Perinatale. Proposta: lineeguida per la prevenzione delle infezioni perinatali da streptococco $\beta$-emolitico di gruppo B. Boll Soc Ital Med Perinatale 1996;1:21-4.

18 Berardi A, Lugli L, Baronciani D, etal. GBS Prevention Working Group of Emilia-Romagna. Group B streptococcal infections in a northern region of Italy. Pediatrics 2007;120:e487-93. .10.1542/peds.2006-3246 17766492

19 Sociedad Espanola de Ginecologia y Obstetricia (SEGO), Sociedad Espanola de Neonatologia (SEN), Sociedad Espanola de Enfermedades Infecciosas y Microbiologia
Clinica (SEIMC), et al. Prevention of perinatal group B streptococcal infections: revised Spanish recommendations 2012. Prog Obstet Ginecol 2012;55:337-46.

10.1016/j.pog.2012.02.003

20 López Sastre JB, Fernández Colomer B, Coto Cotallo GD, Ramos Aparicio AGrupo de Hospitales Castrillo. Trends in the epidemiology of neonatal sepsis of vertical transmission in the era of group B streptococcal prevention. Acta Paediatr 2005;94:451-7. 10.1111/j.1651-2227.2005.tb01917.x 16092460

21 Schrag SJ, Zywicki S, Farley MM, etal . Group B streptococcal disease in the era of intrapartum antibiotic prophylaxis. N Engl J Med 2000;342:15-20. 10.1056/NEJM200001063420103 10620644

22 Centers for Disease Control and Prevention (CDC). Early-onset and late-onset neonatal group B streptococcal disease-United States, 1996-2004. MMWR Morb Mortal Wkly Rep 2005;54:1205-8.16319814

23 Wilson JMG, Jungner G. Principles and practice of screening for disease. World Health Organization, 1968

24 Seedat F, Taylor-Phillips S, Geppert J, et al. Universal antenatal culture-based screening for maternal Group B Streptococcus (GBS) carriage to prevent early-onset GBS disease. $2016 \mathrm{https}: / /$ legacyscreening.phe.org.uk/groupbstreptococcus.

25 Bazian Ltd. Screening for Group B Streptococcal infection in pregnancy: External review against programme appraisal criteria for the UK National Screening Committee (UK NSC). 2012. https://legacyscreening.phe.org.uk/groupbstreptococcus.

26 Russell NJ, Seale AC, O'Driscoll M, etal. GBS Maternal Colonization Investigator Group. Maternal colonization with group $B$ streptococcus and serotype distribution worldwide: systematic review and meta-analyses. Clin Infect Dis 2017;65(suppl_2):S100-11. $10.1093 /$ cid/cix658 29117327

27 Jones N, Oliver K, Jones Y, Haines A, Crook D. Carriage of group B streptococcus in pregnant women from Oxford, UK. J Clin Pathol 2006;59:363-6. 10.1136/jcp.2005.029058 16473927

28 Colbourn T, Gilbert R. An overview of the natural history of early onset group B streptococcal disease in the UK. Early Hum Dev 2007;83:149-56. 10.1016/j.earlhumdev.2007.01.004 17300884

29 O'Sullivan C, Heath PTBritish Pediatric Surveillance Unit. Group B Streptococcal (GBS) disease in UK and Irish infants younger than 90 days, 2014-2015, 2016

30 Heath PT, Balfour G, Weisner AM, etal. PHLS Group B Streptococcus Working Group. Group B streptococcal disease in UK and Irish infants younger than 90 days. Lancet 2004;363:292-4. 10.1016/S0140-6736(03)15389-5 14751704

31 Eastwood KA, Craig S, Sidhu H, etal . Prevention of early-onset Group B Streptococcal disease - the Northern Ireland experience. BJOG 2015;122:361-7. 10.1111/1471-0528.12841 24861487

32 Matsubara K, Hoshina K, Kondo M, etal . Group B streptococcal disease in infants in the first year of life: a nationwide surveillance study in Japan, 2011-2015. Infection 2017:45:449-58. 10.1007/s15010-017-0995-2 28236250

33 Matsubara K, Hoshina K, Suzuki Y. Early-onset and late-onset group B streptococcal disease in Japan: a nationwide surveillance study, 2004-2010. Int $J$ Infect Dis 2013;17:e379-84. 10.1016/.ijid.2012.11.027 23305911

34 Kenyon S, Brocklehurst P. Screening and management of early onset group B streptococcus during labour. BJOG 2011;118:889-89, author reply 889-90. 10.1111/j.1471-0528.2011.02956.x 21564484

35 Public Health EnglandUK Standards for Microbiology Investigations. Detection of Carriage of Group B Streptococci. PHE, 2015.

36 Centers for Disease Control and Prevention. Active Bacterial Core Surveillance Report, Emerging Infections Program Network, Group B Streptococcus, 2016. 2018. https://www. cdc.gov/abcs/reports-findings/survreports/gbs16.html

37 Berardi A, Lugli L, Baronciani D, etal. GBS Prevention Working Group of Emilia-Romagna. Group B Streptococcus early-onset disease in Emilia-romagna: review after introduction of a screening-based approach. Pediatr Infect Dis J 2010;29:115-21. 10.1097/INF.0b013e3181b83cd9 19915512

38 Alhhazmi A, Hurteau D, Tyrrell GJ. Epidemiology of Invasive Group B Streptococca Disease in Alberta, Canada, from 2003 to 2013. J Clin Microbiol 2016;54:1774-81. 10.1128/JCM.00355-16 27098960

39 O'Sullivan C, Lamagni T, Efstratiou A, etal . P3 Group B Streptococcal (GBS) disease in UK and Irish infants younger than 90 days, 2014-2015. Arch Dis Child 2016;101(Suppl 1):A2-2. 10.1136/archdischild-2016-310863.3

40 Office for National Statistics. Dataset: vital statistics: population and health reference tables. UK. 2016. http://www.ons.gov.uk/peoplepopulationandcommunity/ populationandmigration/populationestimates/datasets/ vitalstatisticspopulationandhealthreferencetables.

41 Hospital Episodes Statistics. NHS maternity statistics-England, 2004-2005. NHS Digital; 2006. https://digital.nhs.uk/catalogue/PUB01674.

42 Hospital Episodes Statistics. NHS maternity statistics-England, 2014-2015 NHS Digital; 2015. https://digital.nhs.uk/catalogue/PUB19127.

43 Bevan D, White A, Marshall J, and Peckham C. Modelling the effect of introduction of antenatal screening for Group B Streptococcus in the UK (in press). BMJ Open

44 Colbourn T, Asseburg C, Bojke L, etal. Prenatal screening and treatment strategies to prevent group B streptococcal and other bacterial infections in early infancy: cost-effectiveness and expected value of information analyses. Health Technol Assess 2007;11:1-226, iii. 10.3310/hta11290 17651659

45 Angstetra D, Ferguson J, Giles WB. Institution of universal screening for Group B streptococcus (GBS) from a risk management protocol results in reduction of early-onset GBS disease in a tertiary obstetric unit. Aust N Z J Obstet Gynaecol 2007;47:378-82. 10.1111/j.1479-828X.2007.00760.x 17877594

46 Seedat F, Stinton C, Patterson J, etal . Adverse events in women and children who have received intrapartum antibiotic prophylaxis treatment: a systematic review. BMC Pregnancy Childbirth 2017;17:247. 10.1186/s12884-017-1432-3 28747160

47 Aloisio I, Mazzola G, Corvaglia LT, etal . Influence of intrapartum antibiotic prophylaxis against group B Streptococcus on the early newborn gut composition and evaluation of the anti-Streptococcus activity of Bifidobacterium strains. Appl Microbiol Biotechnol 2014;98:6051-60.24687755

48 Aloisio I, Quagliariello A, De Fanti S, etal . Evaluation of the effects of intrapartum antibiotic prophylaxis on newborn intestinal microbiota using a sequencing approach targeted to multi hypervariable 16S rDNA regions. Appl Microbiol Biotechnol 2016;100:5537-46. 10.1007/s00253-016-7410-2 26971496

49 Arboleya S, Sánchez B, Milani C, etal . Intestinal microbiota development in preterm neonates and effect of perinatal antibiotics. J Pediatr 2015;166:538-44. 10.1016/.jpeds.2014.09.04125444008 
50 Arboleya S, Sánchez B, Solís G, etal . Impact of Prematurity and Perinatal Antibiotics on the Developing Intestinal Microbiota: A Functional Inference Study. Int J Mol Sci 2016;17:E649. 10.3390/ijms17050649 27136545

51 Corvaglia L, Tonti G, Martini S, etal . Influence of Intrapartum Antibiotic Prophylaxis for Group B Streptococcus on Gut Microbiota in the First Month of Life. J Pediatr Gastroentero Nutr 2016;62:304-8. 10.1097/MPG.0000000000000928 26237371

52 Jauréguy F, Carton M, Panel P, Foucaud P, Butel MJ, Doucet-Populaire F. Effects of intrapartum penicillin prophylaxis on intestinal bacterial colonization in infants. $J$ Clin Microbiol 2004;42:5184-8. 10.1128/JCM.42.11.5184-5188.2004 15528713

53 Azad MB, Konya T, Persaud RR, etal . Impact of maternal intrapartum antibiotics, method of birth and breastfeeding on gut microbiota during the first year of life: a prospective cohort study. BJOG 2015;123:983-93. 10.1111/1471-0528.13601. 26412384

54 Mazzola G, Murphy K, Ross RP, etal . Early gut microbiota perturbations following intrapartum antibiotic prophylaxis to prevent group B streptococcal disease. PLoS One 2016;11:e0157527. 10.1371/journal.pone.0157527 27332552

55 Kenyon S, Pike K, Jones DR, etal . Childhood outcomes after prescription of antibiotics to pregnant women with spontaneous preterm labour: 7-year follow-up of the ORACLE II trial. Lancet 2008;372:1319-27. 10.1016/S0140-6736(08)61203-9 18804276

56 Ashkenazi-Hoffnung L, Melamed N, Ben-Haroush A, Livni G, Amir J, Bilavsky E. The association of intrapartum antibiotic exposure with the incidence and antibiotic resistance of infantile late-onset serious bacterial infections. Clin Pediatr (Phila) 2011;50:827-33. 10.1177/0009922811406260 21885435

57 Glasgow TS, Young PC, Wallin J, etal. Association of intrapartum antibiotic exposure and late-onset serious bacterial infections in infants. Pediatrics 2005;116:696-702. 10.1542/peds.2004-2421 16140710

58 Gordon M, Samuels P, Shubert P, Johnson F, Gebauer C, lams J. A randomized, prospective study of adjunctive ceftizoxime in preterm labor. Am J Obstet Gynecol 1995;172:1546-52. 10.1016/0002-9378(95)90494-8 7755069

59 Roca A, Oluwalana C, Bojang A, etal . Oral azithromycin given during labour decreases bacterial carriage in the mothers and their offspring: a double-blind randomized trial. Clin Microbiol Infect 2016;22:565.e1-9. 10.1016/..cmi.2016.03.005 27026482

60 Stoll BJ, Hansen N, Fanaroff AA, etal . Changes in pathogens causing early-onset sepsis in very-low-birth-weight infants. N Engl J Med 2002;347:240-7. 10.1056/NEJMoa012657 12140299

61 Cox LM, Yamanishi S, Sohn J, etal . Altering the intestinal microbiota during a critical developmental window has lasting metabolic consequences. Cell 2014;158:705-21. 10.1016/j.cell.2014.05.052 25126780

62 Francino MP. Antibiotics and the Human Gut Microbiome: Dysbioses and Accumulation of Resistances. Front Microbiol 2016:6:1543. 10.3389/fmicb.2015.01543 26793178

$63 \mathrm{Li}$ Q, Han Y, Dy ABC, Hagerman RJ. The Gut Microbiota and Autism Spectrum Disorders. Front Cell Neurosci 2017;11:120. 10.3389/fncel.2017.00120 28503135

64 Saari A, Virta LJ, Sankilampi U, Dunkel L, Saxen H. Antibiotic exposure in infancy and risk of being overweight in the first 24 months of life. Pediatrics 2015;135:617-26. 10.1542/peds.2014-3407 25825533

65 Huang J, Li S, Li L, Wang X, Yao Z, Ye X. Alarming regional differences in prevalence and antimicrobial susceptibility of group B streptococci in pregnant women: A systematic review and meta-analysis. J Glob Antimicrob Resist 2016;7:169-77. 10.1016/j.jgar.2016.08.010 27837713

66 Phares CR, Lynfield R, Farley MM, etal. Active Bacterial Core surveillance/Emerging Infections Program Network. Epidemiology of invasive group B streptococcal disease in the United States, 1999-2005. JAMA 2008;299:2056-65.

10.1001/jama.299.17.2056 18460666

67 Department of Health. UK five year antimicrobial resistance strategy 2013 to 2018. 2013. https://www.gov.uk/government/publications/uk-5-year-antimicrobial-resistance-strategy2013-to-2018

68 Verani JR, McGee L, Schrag SJDivision of Bacterial Diseases, National Center for Immunization and Respiratory Diseases, Centers for Disease Control and Prevention (CDC). Prevention of perinatal group $B$ streptococcal disease--revised guidelines from CDC, 2010. MMWR Recomm Rep 2010;59(RR-10):1-36.21088663

69 O'Connor M, Nair M, Kurinczuk J, etal . UKOSS Annual Report 2016. National Perinatal Epidemiology Unit, 2016

70 McCall SJ, Bunch KJ, Brocklehurst P, etal . The incidence, characteristics, management and outcomes of anaphylaxis in pregnancy: a population-based descriptive study. BJOG 2018-125.965-71. 10.1111/1471-0528.15041.29193647

71 Lin FY, Troendle JF. Hypothesis: neonatal respiratory distress may be related to asymptomatic colonization with group B streptococci. Pediatr Infect Dis J 2006;25:884-8. 10.1097/01.inf.0000239322.58890.94 17006281

72 Dinsmoor MJ, Viloria R, Lief L, Elder S. Use of intrapartum antibiotics and the incidence of postnatal maternal and neonatal yeast infections. Obstet Gynecol 2005;106:19-22. 10.1097/01.AOG.0000164049.12159.bd 15994612
73 Wohl DL, Curry WJ, Mauger D, Miller J, Tyrie K. Intrapartum antibiotics and childhood atopic dermatitis. J Am Board Fam Med 2015;28:82-9.

10.3122/jabfm.2015.01.140017 25567826

74 Bauserman MS, Laughon MM, Hornik CP, etal . Group B Streptococcus and Escherichia coli infections in the intensive care nursery in the era of intrapartum antibiotic prophylaxis. Pediatr Infect Dis J 2013;32:208-12. 10.1097/INF.0b013e318275058a. 23011013

75 Ecker KL, Donohue PK, Kim KS, Shepard JA, Aucott SW. The impact of group B Streptococcus prophylaxis on early onset neonatal infections. J Neonatal Perinatal Med 2013;6:37-44. 10.3233/NPM-1363312. 24246457

76 Vergani P, Patanè L, Colombo C, Borroni C, Giltri G, Ghidini A. Impact of different prevention strategies on neonatal group B streptococcal disease. Am J Perinatol 2002;19:341-8. 10.1055/s-2002-34464 12357426

77 Schrag SJ, Farley MM, Petit S, etal . Epidemiology of invasive early-onset neonatal sepsis, 2005 to 2014. Pediatrics 2016;138:e20162013. 10.1542/peds.2016-2013 27940705

78 Weston EJ, Pondo T, Lewis MM, etal . The burden of invasive early-onset neonatal sepsis in the United States, 2005-2008. Pediatr Infect Dis J 2011;30:937-41. 10.1097/INF.0b013e318223bad2 21654548

79 Lukacs SL, Schrag SJ. Clinical sepsis in neonates and young infants, United States, 1988-2006. J Pediatr 2012;160:960-5.e1. 10.1016/j.jpeds.2011.12.023 22261508

80 Kurz E, Davis D. Routine culture-based screening versus risk-based management for the prevention of early-onset group B streptococcus disease in the neonate: a systematic review. JBI Database System Rev Implement Rep 2015;13:206-46. 10.11124/jbisrir-2015-1876 26447057

81 Gopal Rao G, Nartey G, McAree T, etal . Outcome of a screening programme for the prevention of neonatal invasive early-onset group B Streptococcus infection in a UK maternity unit: an observational study. BMJ Open 2017;7:e014634. 10.1136/bmjopen-2016-014634 28420662

82 Gopal Rao G, Townsend J, Stevenson D, etal . Early-onset group B $<e m>$ Streptococcus $</$ em $>$ (EOGBS) infection subsequent to cessation of screening-based intrapartum prophylaxis: findings of an observational study in West London, UK. BMJ Open 2017;7. 10.1136/bmjopen-2017-018795

83 Cox E, Martin BC, Van Staa T, Garbe E, Siebert U, Johnson ML. Good research practices for comparative effectiveness research: approaches to mitigate bias and confounding in the design of nonrandomized studies of treatment effects using secondary data sources: the International Society for Pharmacoeconomics and Outcomes Research Good Research Practices for Retrospective Database Analysis Task Force Report--Part II. Value Health 2009;12:1053-61. 10.1111/j.1524-4733.2009.00601.x 19744292

84 Grimes DA, Schulz KF. Bias and causal associations in observational research. Lancet 2002;359:248-52. 10.1016/S0140-6736(02)07451-2 11812579

85 Horváth B, Grasselly M, Bödecs T, Boncz I, Bódis J. Screening pregnant women for group $B$ streptococcus infection between 30 and 32 weeks of pregnancy in a population at high risk for premature birth. Int J Gynaecol Obstet 2013;122:9-12. 10.1016/j.jigo.2013.01.027. 10.1016/j.jigo.2013.01.027 23579102

86 Taminato M, Fram D, Torloni MR, Belasco AG, Saconato H, Barbosa DA. Screening for group B Streptococcus in pregnant women: a systematic review and meta-analysis. Rev Lat Am Enfermagem 2011;19:1470-8. 10.1590/S0104-11692011000600026 22249684

87 Main EK, Slagle T. Prevention of early-onset invasive neonatal group B streptococcal disease in a private hospital setting: the superiority of culture-based protocols. Am J Obstet Gynecol 2000;182:1344-54. 10.1067/mob.2000.106245 10871448

88 Chen KT, Tuomala RE, Cohen AP, Eichenwald EC, Lieberman E. No increase in rates of early-onset neonatal sepsis by non-group B Streptococcus or ampicillin-resistant organisms. Am J Obstet Gynecol 2001;185:854-8. 10.1067/mob.2001.117354 11641665

89 Schrag SJ, Zell ER, Lynfield R, etal. Active Bacterial Core Surveillance Team. A population-based comparison of strategies to prevent early-onset group B streptococcal disease in neonates. N Engl J Med 2002;347:233-9. 10.1056/NEJMoa020205 12140298

90 Eisenberg E, Craig AS, Gautam S, etal . Beyond screening: identifying new barriers to early onset group B streptococcal disease prevention. Pediatr Infect Dis J 2005;24:520-4. 10.1097/01.inf.0000164765.12808.26 15933562

91 Raffle A, Gray M. Screening: Evidence and Practice. Oxford University Press, 200710.1093/acprof:oso/9780199214495.001.0001

92 Brocklehurst P. Screening for Group B streptococcus should be routine in pregnancy: AGAINST: current evidence does not support the introduction of microbiological screening for identifying carriers of Group B streptococcus. BJOG 2015;122:368. 10.1111/1471-0528.13085 25623574

93 Cools P, Melin P. Group B Streptococcus and perinatal mortality. Res Microbiol 2017; 168:793-801. 10.1016/..resmic.2017.04.002 28435137

94 UK National Screening Committee. Early onset streptococcal (EOGBS) disease: a report of a modelling exercise: UK NSC, 2016.

Published by the BMJ Publishing Group Limited. For permission to use (where not already granted under a licence) please go to http://group.bmj.com/group/rights-licensing/ permissions 


\section{Figure}

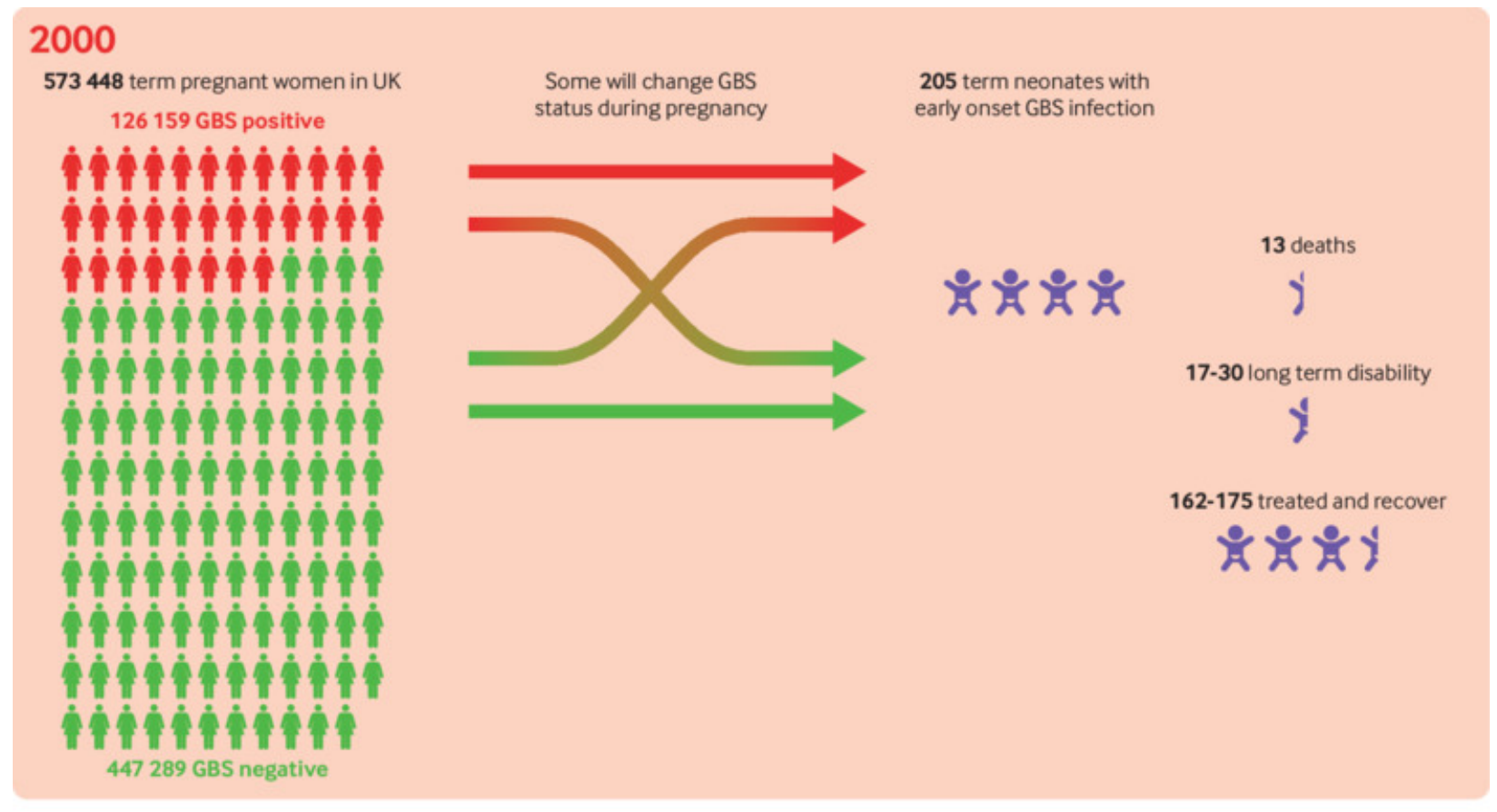

\section{4}

631512 term pregnant women in UK

Some will change GBS status during pregnancy
350 term neonates with early onset GBS infection
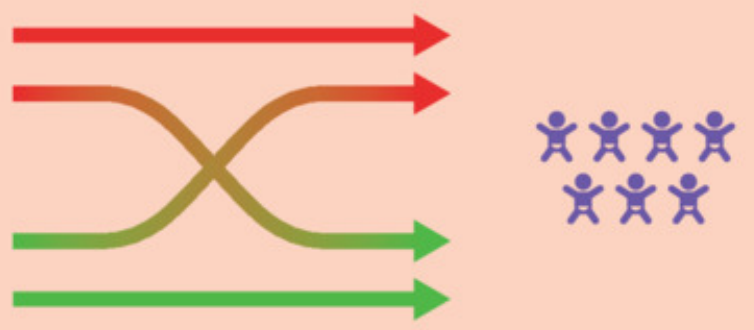

10 deaths

30-54 long term disability<smiles>C1=C2C=C2C1</smiles>

286-310 treated and recover

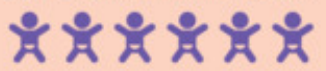

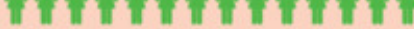

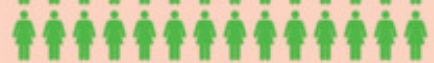

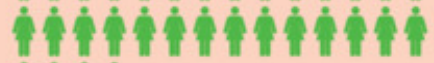

คें̂ें

492579 GBS negative

Fig 1 Natural history of GBS in a hypothetical cohort of term pregnant women in 2000 (no national prevention guideline) and 2014 (risk based national prevention guideline). GBS=group B streptococcus. Owing to the uncertainties of the data, the numbers should be treated cautiously for a sense of scale but not as exact estimates. Data estimates and sources: Pregnant women available for screening in 2000 and 2014: all live births taken from the Office for National Statistics ${ }^{40}$ then elective caesarean sections and preterm births ( $<37$ weeks) were removed from the cohort using Hospital Episodes Statistics estimates, ${ }^{41}{ }^{42}$ as babies born by elective caesarean section are not at risk of early onset GBS infection and preterm births are not eligible for screening. Rate of preterm births in 2000 is taken from 2004-05. Maternal GBS carriage: $22 \% .{ }^{43}$ Number of cases of early onset infection and mortality taken from the British Paediatric Surveillance Unit study. ${ }^{29}{ }^{30}$ Long term disability: 8.7-15.8\% of surviving early onset cases. ${ }^{31-33}$ Short term early onset GBS infection morbidity: meningitis $13.2 \%$, sepsis $63.1 \%$, pneumonia $23.7 \% .^{29}$ Early onset GBS infection cases with maternal risk factors: $33-37 \%$ of cases will have at least one risk factor for intrapartum antibiotic prophylaxis. ${ }^{29}$ 